\title{
A Cross-sectional and Longitudinal Study of Travel by Walking Before and After School among Eighth Grade Girls
}

\author{
Brit I. Saksvig, Ph.D., \\ Department of Epidemiology and Biostatistics, University of Maryland School of Public Health, \\ 2316 SPH Building, College Park, MD 20742, Tel. (301) 405-2491 Fax (301) 405-5578, \\ bsaksvig@umd.edu
}

\author{
Larry S. Webber, Ph.D., \\ Department of Biostatistics, Tulane University School of Public Health and Tropical Medicine
}

John P. Elder, Ph.D.,

Graduate School of Public Health, San Diego State University

Dianne Ward, Ed. D.,

University of North Carolina at Chapel Hill, Gillings School of Global Public Health, Department of Nutrition

\author{
Kelly R. Evenson, Ph.D., \\ University of North Carolina at Chapel Hill, Gillings School of Global Public Health, Department of \\ Epidemiology
}

\author{
Marsha Dowda, DrPH, \\ Soo Eun Chae, Ph.D., and \\ Korean Educational Development Institute, Seoul, Korea \\ Margarita S. Treuth, Ph.D. \\ Department of Physical Therapy, University of Maryland Eastern Shore
}

Arnold School of Public Health, Department of Exercise Science, University of South Carolina

\begin{abstract}
Purpose-To examine "travel by walking" (TBW) before and after school among eighth grade girls.

Methods-Participants attended 36 middle schools from Arizona, Maryland, Minnesota, New Orleans, California and South Carolina participating in the Trial of Activity for Adolescent Girls (TAAG). The cross-sectional sample consisted of 3,076 eighth grade girls, and the longitudinal sample included 1,017 girls who participated in both $6^{\text {th }}$ and $8^{\text {th }}$ grades. Travel by walking before
\end{abstract}

\footnotetext{
(C) 2012 Society for Adolescent Medicine. Published by Elsevier Inc. All rights reserved. Correspondence to: Brit I. Saksvig.

Publisher's Disclaimer: This is a PDF file of an unedited manuscript that has been accepted for publication. As a service to our customers we are providing this early version of the manuscript. The manuscript will undergo copyediting, typesetting, and review of the resulting proof before it is published in its final citable form. Please note that during the production process errors may be discovered which could affect the content, and all legal disclaimers that apply to the journal pertain.

The content is solely the responsibility of the authors and does not necessarily represent the official views of the NIH.

The longitudinal results were reported in a poster presentation at the American Heart Association's Joint Conference: Nutrition, Physical Activity and Metabolism and Cardiovascular Disease Epidemiology and Prevention 2011 Scientific Sessions in Atlanta, Georgia. The cross-sectional results were reported in a poster presentation at the $3^{\text {rd }}$ International Congress on Physical Activity and Public Health in Toronto, Canada, 2010.
} 
or after school status was determined from the 3-Day Physical Activity Recall (3DPAR). The main outcomes were body mass index (BMI) and physical activity, which was measured by accelerometry, estimated for total physical activity (light, moderate, vigorous) and moderate to vigorous physical activity (MVPA).

Results-Eighth grade girls who reported TBW had 4 more minutes (95\% confidence interval ([CI], 2.1-6.1.) of MVPA before and after school than non-walkers, and 2 more minutes of MVPA (95\% CI, 1.1-3.1) on an average weekday. In the longitudinal sample, girls who reported TBW before and after school in both $6^{\text {th }}$ and $8^{\text {th }}$ grades (consistent walkers) accumulated more minutes of MVPA for an average weekday than inconsistent walkers in both sixth (27 min. $\pm 2.2 \mathrm{vs} .25 \mathrm{~min}$. $\pm 1.9 ; \mathrm{p}=.03$ ) and eighth grades (28 min. \pm 2.6 vs. $25 \min . \pm 2.3 ; \mathrm{p}=.003$ ). There were no differences in BMI by walking status.

Conclusions-Adolescent girls who reported TBW before and after school accumulated more minutes of MVPA than non-walkers. Efforts to prevent the decline in walking to school in middle school girls could contribute to their overall physical activity.

\section{Keywords}

Active travel; Adolescents; Girls; Physical activity; School; Travel by walking; Transportation

\section{IMPLICATIONS AND CONTRIBUTIONS}

This study demonstrates that travel by walking before and after school contributes to adolescent girls time spent in moderate to vigorous physical activity. Efforts to prevent the decline in walking to school in middle school girls could contribute to overall physical activity.

\section{INTRODUCTION}

The promotion of physical activity among youth can help address the obesity epidemic and establish early lifestyle physical activity patterns that can be extended into adolescence and adulthood [1]. Recent studies have shown that youth who actively commute (walking or bicycling) have higher levels of physical activity than those who use motorized transport [2]. Active commuting is a strategy that may increase overall physical activity and contribute to reducing overweight [3-5]. Sirard and Slater [6] conducted a review of more than 30 years of research, finding that American children are far less likely to actively commute than their European counterparts. This, in part, may be due to differences in urban physical environments and land use, as they influence physical activity in the form of walking and bicycling for transport [7]. Understanding how active commuting changes as children and adolescents mature could provide valuable information for intervention programs. Few studies have examined active commuting patterns longitudinally among children and adolescents [8-10].

A previous analysis using data from the Trial of Activity for Adolescent Girls (TAAG) examined the contribution of before- and after-school walking to total physical activity in $6^{\text {th }}$ grade girls [11]. In that study, girls who reported travel by walking (TBW) before and after school had 5 more minutes of moderate to vigorous physical activity (MVPA) and 14 more minutes of total physical activity per day than girls who did not report this activity, as measured by accelerometry.

This manuscript builds upon that study by describing TBW before and after school among eighth grade girls and longitudinally examines TBW in a sample of girls who were measured both in the $6^{\text {th }}$ grade and $8^{\text {th }}$ grade. The major purposes of this study were to 1 ) 
determine if the patterns of TBW before and after school were similar between $6^{\text {th }}$ and $8^{\text {th }}$ grade girls, and 2) examine whether there were differences in minutes per day of total physical activity, MVPA, and body mass index (BMI) among girls who reported TBW before and after school in both $6^{\text {th }}$ and $8^{\text {th }}$ grades compared to girls who did not report TBW in both time periods.

\section{METHODS}

\section{Participants}

Participants consisted of $8^{\text {th }}$ grade girls in 2005 enrolled in the TAAG Study, a multi-center, group-randomized trial sponsored by the National Heart, Lung, and Blood Institute to increase opportunities for and participation in physical activity for middle school-aged girls, details provided elsewhere [12-14]. Briefly, participants were recruited from six middle schools at each of the six university-based field centers located in and around Tucson, Arizona; San Diego, California; New Orleans, Louisiana; Baltimore, Maryland; Minneapolis, Minnesota; and Columbia, South Carolina. The TAAG study design included two cross-sectional samples of middle school girls; one drawn from $6^{\text {th }}$ graders in the spring of 2003, a second drawn from $8^{\text {th }}$ graders in the spring of 2005 after implementation of the 2 -year intervention. Sixty healthy $6^{\text {th }}$ grade girls were randomly selected from six schools at each of the six TAAG field sites for measurements in the spring of 2003. In 2005, 120 healthy $8^{\text {th }}$ grade girls were randomly selected to undergo the same measurements. For longitudinal studies, all of the $8^{\text {th }}$ grade girls who had been measured in the $6^{\text {th }}$ grade in 2003 and who attended a TAAG school in spring 2005 were recruited.

For the sample of $8^{\text {th }}$ grade girls, 3,504 girls consented to be measured; 393 were excluded because they failed to wear the accelerometer for at least 1 day and 35 were excluded for missing data on the 3-Day Physical Activity Recall (3DPAR), with 3,076 participants available for the final analysis. For the longitudinal analysis, 1,592 of the 1,721 girls who were assessed in the $6^{\text {th }}$ grade had complete data for this analysis. Of this group 1,299 were also assessed in the $8^{\text {th }}$ grade. Among those girls, 126 were excluded because they failed to wear the accelerometer for at least 1 day and 156 were excluded because of missing data on the 3DPAR in the $8^{\text {th }}$ grade. Thus, 1,017 girls provided data for the longitudinal analyses.

The study protocol was approved by each participating institution's Human Subjects Review Board. Each participant's parent or guardian provided written informed consent, and all participants assented to participate. Consent for measurement was obtained for $80 \%$ of the random sample.

\section{Measurements}

The same measurement procedures were followed in the $8^{\text {th }}$ grade as the $6^{\text {th }}$ grade and are described in more detail elsewhere $[11,13]$. In brief, age, race/ethnicity, participation in free and reduced priced lunch (measure of socioeconomic status (SES)), and perception of neighborhood factors were obtained from each participant by questionnaire. Ten questions were asked regarding the girls' perceptions of their neighborhoods, including perceived safety (e.g., safe to walk or jog in the neighborhood), aesthetics (e.g., many interesting things to look at in the neighborhood) and access to facilities near home (e.g., places to walk to from home). Participants rated each item on a 5-point Likert scale, ranging from disagree a lot (1) to agree a lot (5). These measures have evidence for reliability [15] and several items were shown to be associated with non-school MVPA and BMI cross-sectionally [16] and with a 2-year decline in MVPA among the TAAG cohort [17]. 
Anthropometric measurements-Standing height was measured without shoes using a portable stadiometer (Shorr Productions) to the nearest $0.1 \mathrm{~cm}$. Body weight was assessed using a digital scale (Seca 880) and measured to the nearest $0.1 \mathrm{~kg}$. Weight and height were measured two times each following a standardized protocol and the average of the two measures were calculated. BMI was calculated as weight $(\mathrm{kg}) /$ height $(\mathrm{m})^{2}$.

Accelerometry-Participants wore a uniaxial ActiGraph accelerometer (model 7164; Health One Technology, Fort Walton Beach, FL) for seven consecutive days, resulting in six complete days of data. ActiGraph counts (epoch $=30$ seconds) were summarized by quantifying the time (minutes) spent at different intensity levels. Missing accelerometer data was then imputed based on the expectation maximization algorithm [18]. Evaluation of our imputation procedure indicated that it provided valid results, even when data were not missing at random [14].

Activity intensity thresholds established for the TAAG Study were $\mathbf{5 0}$ counts per 30 seconds for sedentary behavior, 51 to 1499 counts per 30 seconds for light activity, and $\geq 1500$ counts per 30 seconds for MVPA [19]. The threshold of $\geq 1500$ counts per 30 seconds for MVPA corresponded approximately to the lower bound for a 3.5-mph walk and represents an activity intensity of 4.6 metabolic equivalents (METs). A slightly lower cut point was also defined, corresponding to the lower bound for a 2.5 -mph walk (3 METs). From this point on, MVPA refers to the 4.6 MET threshold and the 3 MET threshold is referred to as MVPA (3 METs).

For this study, we summed the minutes of total physical activity (sum of light, moderate, and vigorous activity) and MVPA accumulated before school, after school, and before and after school combined. "Before school" was defined as 6 AM to the school start-bell time and "after school" was defined as the school end-bell time to 5 PM for each TAAG middle school.

Self-reported Physical Activity-A modified version of the 3-Day Physical Activity Recall (3DPAR) was used to provide context regarding the physical activities that the participants performed [20]. The 3DPAR itself is a modification of the Previous Day's Physical Activity Recall (PDPAR), which has evidence for validity among youth [21, 22]. The 3DPAR was significantly correlated with MTI ActiGraph counts in adolescent girls for MVPA $(r=0.28-0.31)[20]$.

The 3DPAR form consisted of three grids (one for each day) divided into 30-minute segments/blocks. Participants chose and recorded the code number of the predominant activity that they performed during each block of time. Participants then chose an intensity level (light, moderate, hard or very hard) at which they performed the activity. All surveys were taken in a classroom or gymnasium setting in which girls were given instructions from a standardized script used across all sites.

Geographic Information Systems (GIS) Measures-Valid addresses were obtained for 2,947 of the participants and were geocoded using ArcGIS 9.0 (Environmental Systems Research Institute, Inc, Redlands, CA). Using the geocoded addresses, a neighborhood was created, defined as the area within a $1 / 2$ mile buffer surrounding each girl's home. Distance to school was calculated using ArcGIS as the distance from their home to school along the shortest street network distance. Street connectivity (called a "neighborhood connectivity index") was defined as a combination of alpha, beta, and gamma indices, which are measures of the ratio of intersections to street segments [23]. Neighborhood population density was calculated using the 2000 US Census block groups. The total population within each neighborhood was computed by taking the weighted average of the component 
populations across the block groups within a $1 / 2$ mile buffer around the girl's home, with weights proportional to the block group's area in the buffer. The population density was calculated by dividing this total by the area of the buffer.

\section{Statistical Analysis}

Participants were classified as before and after school walkers if they reported TBW on one or more weekdays before or after school on the 3DPAR, using the school bell schedule times for each school. Travel by bicycle was not included because $<1 \%$ of $8^{\text {th }}$ grade girls reported riding a bicycle before or after school.

All analyses used mixed-model regression methods to reflect the group randomization and the nesting of students within schools, sites, and conditions [24]. Differences in sociodemographic and neighborhood variables by walking status were compared. In the mixed procedure, test results (p-values and T-test) were obtained based on their least square means of fixed effect (i.e., walking status), which predicted population margins [25].

Cross-sectional analyses were used to examine the minutes of physical activity (total physical activity, MVPA) by before/after school time periods (before school, after school, before and after school) and an average weekday by TBW status. This was also done for minutes of sedentary behavior. In these models, TBW status (categorized as none and some TBW before and after school) was considered a fixed variable and girl, school, and site as random variables; analyses also controlled for race/ethnicity and SES. The Bonferroni Correction for multiple tests can be used to ensure that the Type I error is controlled.

Longitudinal analyses were used to examine changes in TBW by comparing the minutes of MVPA and total physical activity during the before and after school time periods and for an average weekday between girls who reported TBW in both $6^{\text {th }}$ and $8^{\text {th }}$ grades (called consistent walkers) and girls who reported TBW in $6^{\text {th }}$ grade but not $8^{\text {th }}$ grade, girls who reported TBW in $8^{\text {th }}$ grade but not $6^{\text {th }}$ grade, and girls who never reported walking (all three combined and called consistent walkers). Change in minutes of physical activity by consistent and inconsistent TBW status were compared by subtracting minutes of physical activity in the sixth grade from $8^{\text {th }}$ grade results. Statistical significance was interpreted at $\mathrm{p}<0.05$ and all analyses were completed using Proc Mixed in SAS 8.02 for Windows [25].

\section{RESULTS}

The mean+/-SD age for $8^{\text {th }}$ grade girls was $14 \pm 0.5$ years and the mean+/-SD BMI was $22.8 \pm 5.3 \mathrm{~kg} / \mathrm{m}^{2}$. The racial and ethnic breakdown was $46 \%$ White, $22 \%$ African American, $21 \%$ Hispanic, and $11 \%$ Multi-Racial/Other. The most frequently reported before and after school physical activity among $8^{\text {th }}$ grade girls was TBW, with $12 \%$ of girls reporting TBW before school and $27 \%$ reporting TBW after school.

More Hispanics, African American, and multi-racial/other girls reported TBW than White girls (Table 1). More walkers reported receiving free or reduced priced lunches than nonwalkers. Of the 10 neighborhood perception items, $8^{\text {th }}$ grade girls who reported TBW before and after school perceived that there were more interesting places to go within walking distance of home and that sidewalks were available on most of the streets in their neighborhood. Girls' who reported TBW before and after school lived closer to their school and lived in neighborhoods with greater neighborhood connectivity than the non-walkers.

Overall, girls who reported TBW accumulated more minutes of MVPA (using either 3 or 4.6 MET definitions) than girls who did not report TBW during the before, after, and before and after school time periods, and on an average weekday (Table 2). 
Before and after school walkers had longer bouts (8-9 minutes more) of continuous MVPA (3 METs) before school and after school compared to non-walkers. A similar trend in favor of greater activity for before-and after school walkers was noted when we examined the time spent engaged in MVPA ( 3 METs) averaged over the entire day broken down by girls' who reported walking before, after, before and after, and no walking was examined (Table 2 and Figure 1).

\section{Longitudinal Comparison between $6^{\text {th }}$ and $8^{\text {th }}$ Graders}

Of the 1,017 girls who were measured in both $6^{\text {th }}$ grade and $8^{\text {th }}$ grade, $25 \%$ reported TBW before and after school in $6^{\text {th }}$ grade and $30 \%$ reported TBW in $8^{\text {th }}$ grade. One hundred and twenty three girls reported TBW before and after school in both $6^{\text {th }}$ and $8^{\text {th }}$ grades and are considered "consistent walkers", all other participants are considered "in-consistent walkers" (see Figure 2). No meaningful differences in mean BMI were observed between the consistent or inconsistent walkers in $6^{\text {th }}$ grade $\left(20.7 \pm 0.65 \mathrm{~kg} / \mathrm{m}^{2}\right.$ vs. $20.8 \pm 0.41 \mathrm{~kg} / \mathrm{m}^{2}$; $\mathrm{p}=0.9)$ or $8^{\text {th }}$ grade $\left(23.5 \pm 0.83 \mathrm{~kg} / \mathrm{m}^{2}\right.$ vs. $\left.23.3 \pm 0.70 \mathrm{~kg} / \mathrm{m}^{2} ; \mathrm{p}=0.6\right)$.

Consistent walkers maintained more minutes of MVPA for an average weekday in $6^{\text {th }}$ and $8^{\text {th }}$ grades than inconsistent walkers (Figure 3 ). For the before and after school time period, consistent walkers had more minutes of MVPA in $6^{\text {th }}$ grade than inconsistent walkers $(\mathrm{p}=<$. 001). Both consistent and inconsistent walkers increased their minutes of MVPA from the $6^{\text {th }}$ grade; however, the difference in minutes of MVPA in $8^{\text {th }}$ grade between consistent and inconsistent walkers did not reach significance $(\mathrm{p}=0.07)$. There were no differences between consistent and inconsistent walkers in the total activity they accumulated during the before and after school time periods or on an average weekday. Consistent walkers participated in fewer minutes of sedentary pursuits compared to inconsistent walkers in the $6^{\text {th }}$ grade on an average weekday $(497 \pm 10.9$ vs. $511 \pm 9.5 \mathrm{~min} ; \mathrm{p}=0.03)$, but not in $8^{\text {th }}$ grade $(553 \pm 10.5$ vs. $558 \pm 8.8 \mathrm{~min} ; \mathrm{p}=0.4)$.

When examining change in minutes of total activity, MVPA (3.0 and 4.6 METs), and sedentary behavior between $6^{\text {th }}$ and $8^{\text {th }}$ grade in the cohort, there were no differences between consistent and inconsistent walkers (data not shown).

\section{DISCUSSION}

We examined TBW before and after school in adolescent girls in the $8^{\text {th }}$ grade and among the cohort who participated in TAAG in $6^{\text {th }}$ and $8^{\text {th }}$ grade [11]. We found that $8^{\text {th }}$ grade girls who reported TBW before or after school accumulated more minutes of MVPA before school, after school, before and after school combined, and on an average weekday, than those who did not report TBW. However, this finding did not apply to total activity (the sum of minutes of all levels of intensities combined). In addition, these differences were small, but significant, in that the girls who reported TBW had several more minutes of MVPA each day, regardless of the definition of MVPA, than those girls who did not report TBW.

There were no differences in BMI between walkers and non-walkers in the cross-sectional sample of $8^{\text {th }}$ grade girls. There were also no differences in BMI in the longitudinal sample between girls who were consistent walkers and those who were not. Previous studies have found mixed results when examining BMI and active commuting among children and adolescents $[8,10,11,26-29]$. One explanation is that actively commuting to school may not provide enough physical activity to impact BMI, possibly due to the fact that walkers live closer to their schools and that walking to school may only take a few minutes $[3,8]$.

There were differences between walkers and non-walkers by race/ethnicity and participation in free and reduced priced lunch, an indicator of SES. Consistent with previous studies [2, 
30, 31], significantly more walkers were African American and Hispanic than Caucasian. In the current study significantly more walkers participated in free and reduced priced lunch. Studies using different methods for determining SES (school-level, neighborhood SES, percentage of students on welfare) have also demonstrated that lower SES children are relatively more likely to walk to and from school [2]. These differences may be an indication of girls who may be walking out of necessity and not by choice.

Neighborhood factors can influence the interpretation of the findings. [32, 33]. Girls who reported TBW before and after school lived closer to their school and perceived their neighborhoods to have features that were more supportive of physical activity than nonwalkers, such as having many places they like to go within walking distance of their homes. They also lived in neighborhoods that were more connected and lived significantly closer to schools than non-walkers. Previous studies of adolescents found that those living in neighborhoods with greater street connectivity were more likely to actively commute to school [30, 34], while one study found no association [35]. A review by Panter and colleagues [36] found that environmental factors that promoted TBW in children included safety factors, various social interactions (seeing children in the neighborhood, peer support, etc.), and the presence of facilities to assist walking. In addition, distance to school has been found to moderate the contribution of active commuting to physical activity levels-the farther a child lives from school the more time is spent in active travel

In our previous study of $6^{\text {th }}$ grade, girls who reported walking both before and after school accumulated 388 minutes of total physical activity (light, moderate, and vigorous) for an average weekday-14 more minutes than non-walkers [11]. In the $8^{\text {th }}$ grade sample, girls who reported walking both before and after school accumulated 338 minutes of total physical activity, $<1$ minute more than non-walkers. Both walkers and non-walkers respectively showed a 50 minute decrease in total physical activity between $6^{\text {th }}$ and $8^{\text {th }}$ grades; a similar decline was also seen in the longitudinal sample. The drop in minutes of total physical activity appears to be related to decreases in minutes spent in light activity. Girls' appear to be replacing light activity with more sedentary behaviors. Previous studies have also noted this decline in physical activity in adolescent girls [37, 38].

There was also a small decline in minutes of MVPA between $6^{\text {th }}$ and $8^{\text {th }}$ grade. MVPA decreased by 2 minutes in the cross-sectional samples between $6^{\text {th }}$ and $8^{\text {th }}$ grades regardless of walking status; however, girls who reported TBW maintained more minutes of MVPA than non-walkers. In the longitudinal sample, the amount of time spent in MVPA during the before and after school time periods in $8^{\text {th }}$ grade either increased or remained the same as in $6^{\text {th }}$ for both walkers and non-walkers. This could be due to the fact that the more mature and independent $8^{\text {th }}$ grade girls were more able to walk around after school than $6^{\text {th }}$ grade girls.

One difference between this study of $8^{\text {th }}$ grade girls and the $6^{\text {th }}$ grade report [11] was that walkers were condensed into two categories (walkers/non-walkers). The current study also controlled for race/ethnicity and SES, while the previous $6^{\text {th }}$ grade study did not control for these variables.

Strengths of this study are that the TAAG study includes results from an ethnically diverse group of girls in six regions of the United States. While this is not a geographically random sample, the study sites were diverse, as were the study participants. Another strength is that the longitudinal nature of the data allows for the examination of trends over time in selected subsets of the study. Finally, both individual and environmental level measurements were used.

One limitation was the use the 3DPAR to identify girls who reported TBW before and after school as a proxy for an actual "walk to school" variable because this question was not 
asked at baseline. However, using this variable allowed changes to be observed between $6^{\text {th }}$ and $8^{\text {th }}$ grade girls who reported TBW. Additionally, one week of accelerometer measurement represents a short time frame for generalization of a pattern of TBW before and after school. We determined walking status based on reporting walking on one or more weekdays which allows comparison with the $6^{\text {th }}$ grade results [11]. Even though the overall sample is large, the sample sizes became small for particular subsets, particularly for the longitudinal comparisons.

This study demonstrates that TBW before and after school can help adolescent girls increase the amount of time spent in MVPA both during those time periods and for an average weekday. Girls who continued to walk before and after school between sixth and eighth grades maintained more minutes of MVPA than the non-walkers. Efforts to prevent the decline in walking to school in middle school girls, such as a promotion of walking to school, could contribute to their overall physical activity.

\section{Acknowledgments}

This research was funded by grants from the National Institutes of Health (NIH), National Heart, Lung, and Blood Institute (U01HL66858, U01HL66857, U01HL66845, U01HL66856, U01HL66855, U01HL66853, U01HL66852, and R01HL071244).

\section{REFERENCES}

1. Tudor-Locke C, Ainsworth BE, Popkin BM. Active commuting to school: an overlooked source of childrens' physical activity? Sports Med. 2001; 31(5):309-313. [PubMed: 11347681]

2. Davison KK, Werder JL, Lawson CT. Children's active commuting to school: current knowledge and future directions. Prev Chronic Dis. 2008; 5(3):A100. [PubMed: 18558018]

3. Faulkner GE, Buliung RN, Flora PK, et al. Active school transport, physical activity levels and body weight of children and youth: a systematic review. Prev Med. 2009; 48(1):3-8. [PubMed: 19014963]

4. Lee MC, Orenstein MR, Richardson MJ. Systematic review of active commuting to school and childrens physical activity and weight. J Phys Act Health. 2008; 5(6):930-949. [PubMed: 19164826]

5. Sirard JR, Alhassan S, Spencer TR, et al. Changes in physical activity from walking to school. J Nutr Educ Behav. 2008; 40(5):324-326. [PubMed: 18725153]

6. Sirard JR, Slater ME. Walking and Bicycling to School: A Review. American Journal of Lifestyle Medicine. 2008; vol 2:372-396.

7. Saelens BE, Sallis JF, Frank LD. Environmental correlates of walking and cycling: findings from the transportation, urban design, and planning literatures. Ann Behav Med. 2003; 25(2):80-91. [PubMed: 12704009]

8. Heelan KA, Donnelly JE, Jacobsen DJ, et al. Active commuting to and from school and BMI in elementary school children-preliminary data. Child Care Health Dev. 2005; 31(3):341-349. [PubMed: 15840154]

9. Hume C, Timperio A, Salmon J, et al. Walking and cycling to school: predictors of increases among children and adolescents. Am J Prev Med. 2009; 36(3):195-200. [PubMed: 19162431]

10. Rosenberg DE, Sallis JF, Conway TL, et al. Active transportation to school over 2 years in relation to weight status and physical activity. Obesity (Silver Spring). 2006; 14(10):1771-1776. [PubMed: 17062807]

11. Saksvig BI, Catellier DJ, Pfeiffer K, et al. Travel by walking before and after school and physical activity among adolescent girls. Arch Pediatr Adolesc Med. 2007; 161(2):153-158. [PubMed: 17283300]

12. Pate RR, Stevens J, Pratt C, et al. Objectively measured physical activity in sixth-grade girls. Arch Pediatr Adolesc Med. 2006; 160(12):1262-1268. [PubMed: 17146024] 
13. Webber LS, Catellier DJ, Lytle LA, et al. Promoting physical activity in middle school girls: Trial of Activity for Adolescent Girls. Am J Prev Med. 2008; 34(3):173-184. [PubMed: 18312804]

14. Stevens J, Murray DM, Catellier DJ, et al. Design of the Trial of Activity in Adolescent Girls (TAAG). Contemp Clin Trials. 2005; 26(2):223-233. [PubMed: 15837442]

15. Evenson KR, Birnbaum AS, Bedimo-Rung AL, et al. Girls' perception of physical environmental factors and transportation: reliability and association with physical activity and active transport to school. Int J Behav Nutr Phys Act. 2006; 3:28. [PubMed: 16972999]

16. Evenson KR, Scott MM, Cohen DA, et al. Girls' perception of neighborhood factors on physical activity, sedentary behavior, and BMI. Obesity (Silver Spring). 2007; 15(2):430-445. [PubMed: 17299117]

17. Evenson KR, Murray DM, Birnbaum AS, Cohen DA. Examination of perceived neighborhood characteristics and transportation on changes in physical activity and sedentary behavior: The Trial of Activity in Adolescent Girls. Health Place. 2010; 16(5):977-985. [PubMed: 20615746]

18. Catellier DJ, Hannan PJ, Murray DM, et al. Imputation of missing data when measuring physical activity by accelerometry. Med Sci Sports Exerc. 2005; 37(11 Suppl):S555-S562. [PubMed: 16294118]

19. Treuth MS, Schmitz K, Catellier DJ, et al. Defining accelerometer thresholds for activity intensities in adolescent girls. Med Sci Sports Exerc. 2004; 36(7):1259-1266. [PubMed: 15235335]

20. McMurray RG, Ring KB, Treuth MS, et al. Comparison of two approaches to structured physical activity surveys for adolescents. Med Sci Sports Exerc. 2004; 36(12):2135-2143. [PubMed: 15570151]

21. Trost S, Ward D, McGraw B, Pate R. Validity of the Previous Day Physical Activity Recall (PDPAR) in Fifth-Grade Children. Pediatric Exercise Science. 1999; 11(4):341.

22. Weston AT, Petosa R, Pate RR. Validation of an instrument for measurement of physical activity in youth. Med Sci Sports Exerc. 1997; 29(1):138-143. [PubMed: 9000167]

23. Cohen DA, Ashwood JS, Scott MM, et al. Public parks and physical activity among adolescent girls. Pediatrics. 2006; 118(5):e1381-e1389. [PubMed: 17079539]

24. Murray, DM. Design and analysis of group-randomized trials. New York NY: Oxford University Press; 1998.

25. Littell, R.; Milliken, G.; Stroup, W., et al. SAS system for mixed models. Cary, NC, USA: SAS Institute Inc; 1996.

26. Cooper AR, Page AS, Foster LJ, et al. Commuting to school: are children who walk more physically active? Am J Prev Med. 2003; 25(4):273-276. [PubMed: 14580626]

27. Gordon-Larsen P, Nelson MC, Beam K. Associations among active transportation, physical activity, and weight status in young adults. Obes Res. 2005; 13(5):868-875. [PubMed: 15919840]

28. Klein-Platat C, Oujaa M, Wagner A, et al. Physical activity is inversely related to waist circumference in 12-y-old French adolescents. Int J Obes (Lond). 2005; 29(1):9-14. [PubMed: 15278108]

29. Sirard JR, Riner WF Jr, McIver KL, et al. Physical activity and active commuting to elementary school. Med Sci Sports Exerc. 2005; 37(12):2062-2069. [PubMed: 16331130]

30. Braza M, Shoemaker W, Seeley A. Neighborhood design and rates of walking and biking to elementary school in 34 California communities. Am J Health Promot. 2004; 19(2):128-136. [PubMed: 15559713]

31. Evenson KR, Huston SL, McMillen BJ, et al. Statewide prevalence and correlates of walking and bicycling to school. Arch Pediatr Adolesc Med. 2003; 157(9):887-892. [PubMed: 12963594]

32. Panter J, Jones A, Van Sluijs E, et al. The influence of distance to school on the associations between active commuting and physical activity. Pediatr Exerc Sci. 2011; 23(1):72-86. [PubMed: 21467592]

33. Van Sluijs EM, Fearne VA, Mattocks C, et al. The contribution of active travel to children's physical activity levels: cross-sectional results from the ALSPAC study. Prev Med. 2009; 48(6): 519-524. [PubMed: 19272404]

34. Schlossberg M, Greene J, Phillips PP, et al. School trips: effects of urban form and distance on travel mode. J Am Plann Assoc. 2006; 72:337-346. 
35. Kerr J, Rosenberg D, Sallis JF, et al. Active commuting to school: Associations with environment and parental concerns. Med Sci Sports Exerc. 2006; 38(4):787-794. [PubMed: 16679998]

36. Panter JR, Jones AP, van Sluijs EM. Environmental determinants of active travel in youth: A review and framework for future research. Int J Behav Nutr Phys Act. 2008; 5:34. [PubMed: 18573196]

37. Kimm SY, Glynn NW, Kriska AM, et al. Decline in physical activity in black girls and white girls during adolescence. N Engl J Med. 2002; 347(10):709-715. [PubMed: 12213941]

38. Nader PR, Bradley RH, Houts RM, et al. Moderate-to-vigorous physical activity from ages 9 to 15 years. Jama. 2008; 300(3):295-305. [PubMed: 18632544] 


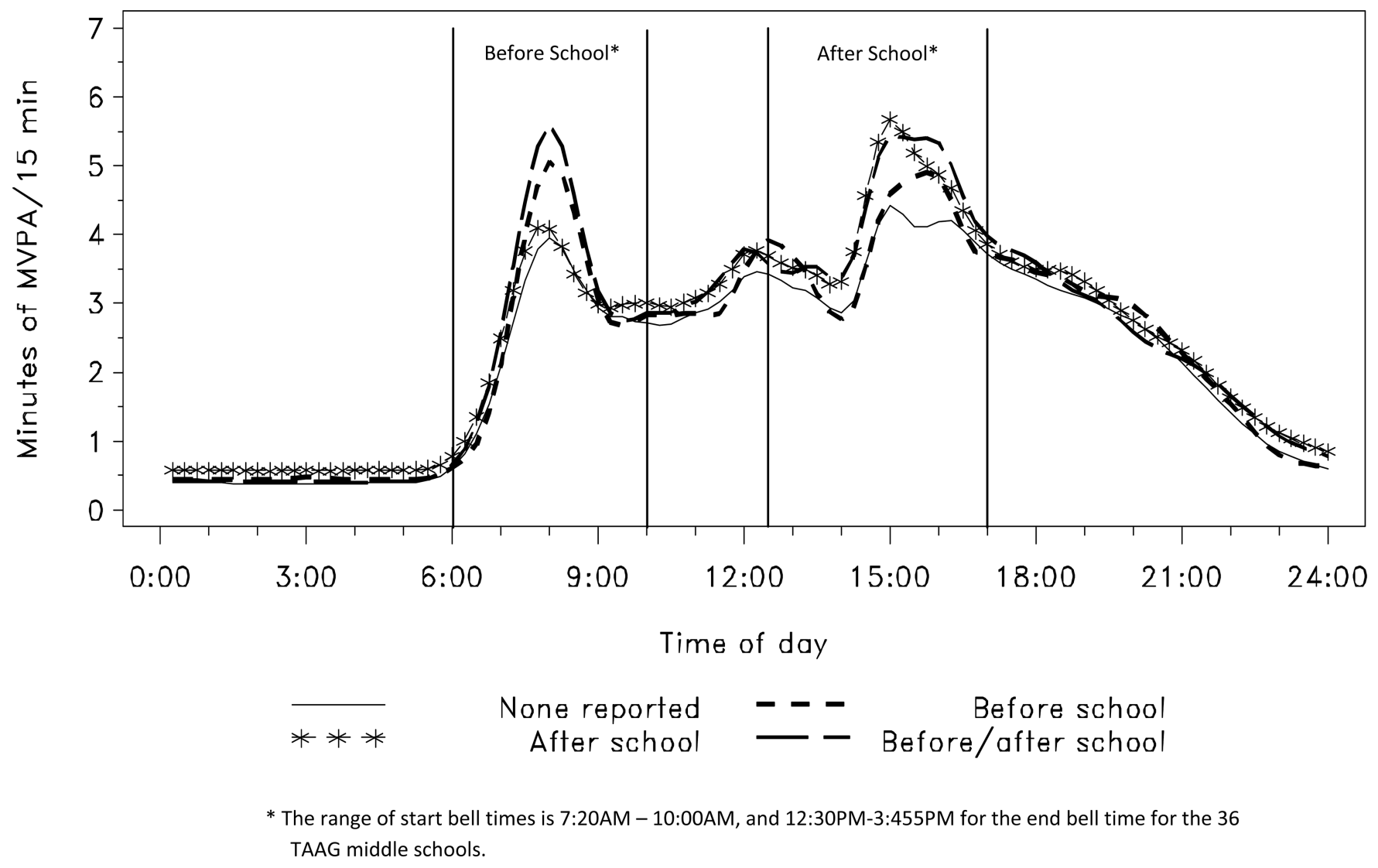

Figure 1.

Average weekday MVPA ( 3 metabolic equivalents) by hour in $8^{\text {th }}$ grade girls who reported and did not report travel by walking before and after school. MVPA indicates moderate to vigorous physical activity. Smoothing parameter=0.075. 


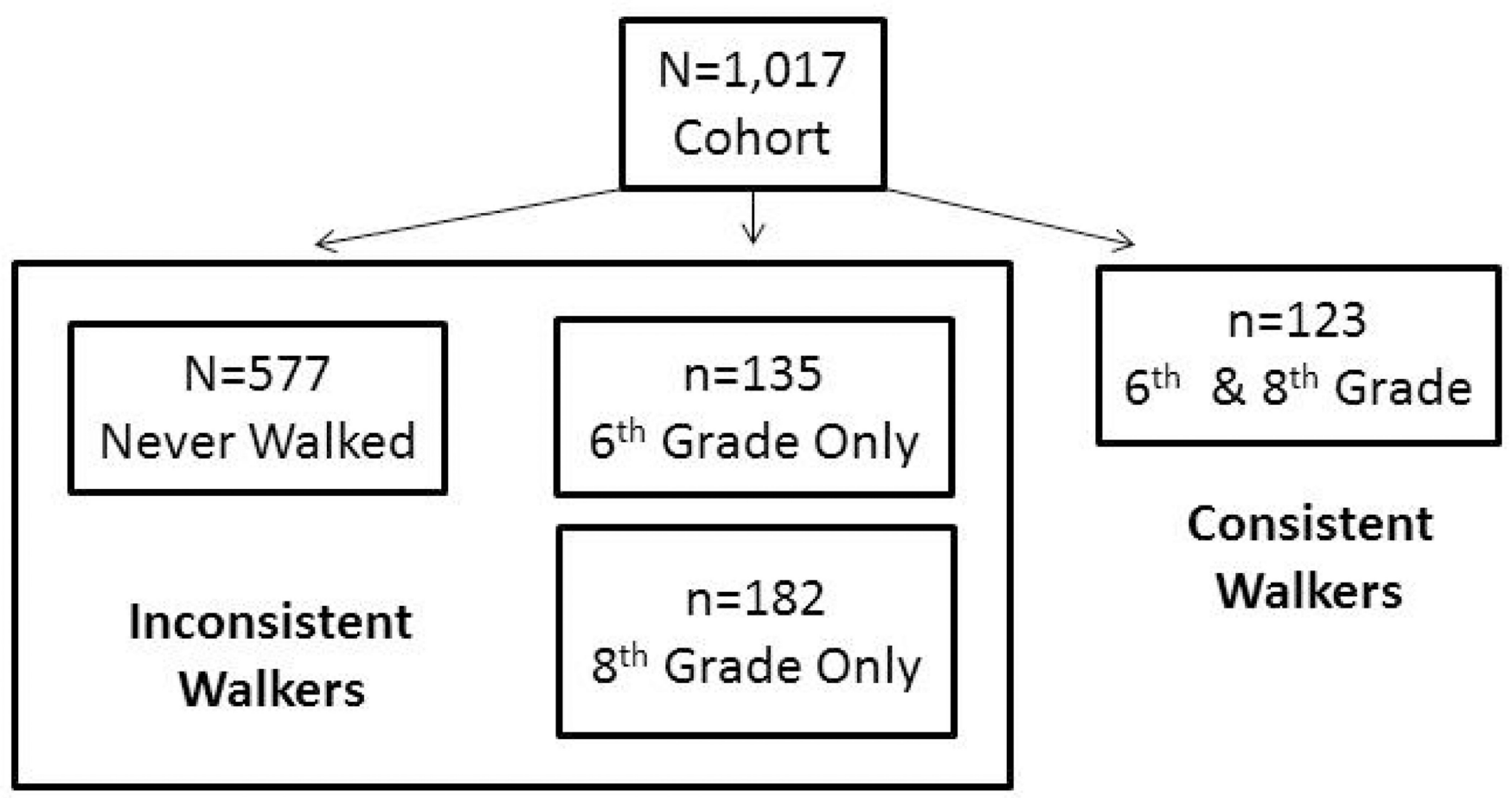

Figure 2.

Description of consistent and inconsistent before and after school travel by walking status for the $6^{\text {th }}-8^{\text {th }}$ grade cohort, $\mathrm{N}=1,017$ 


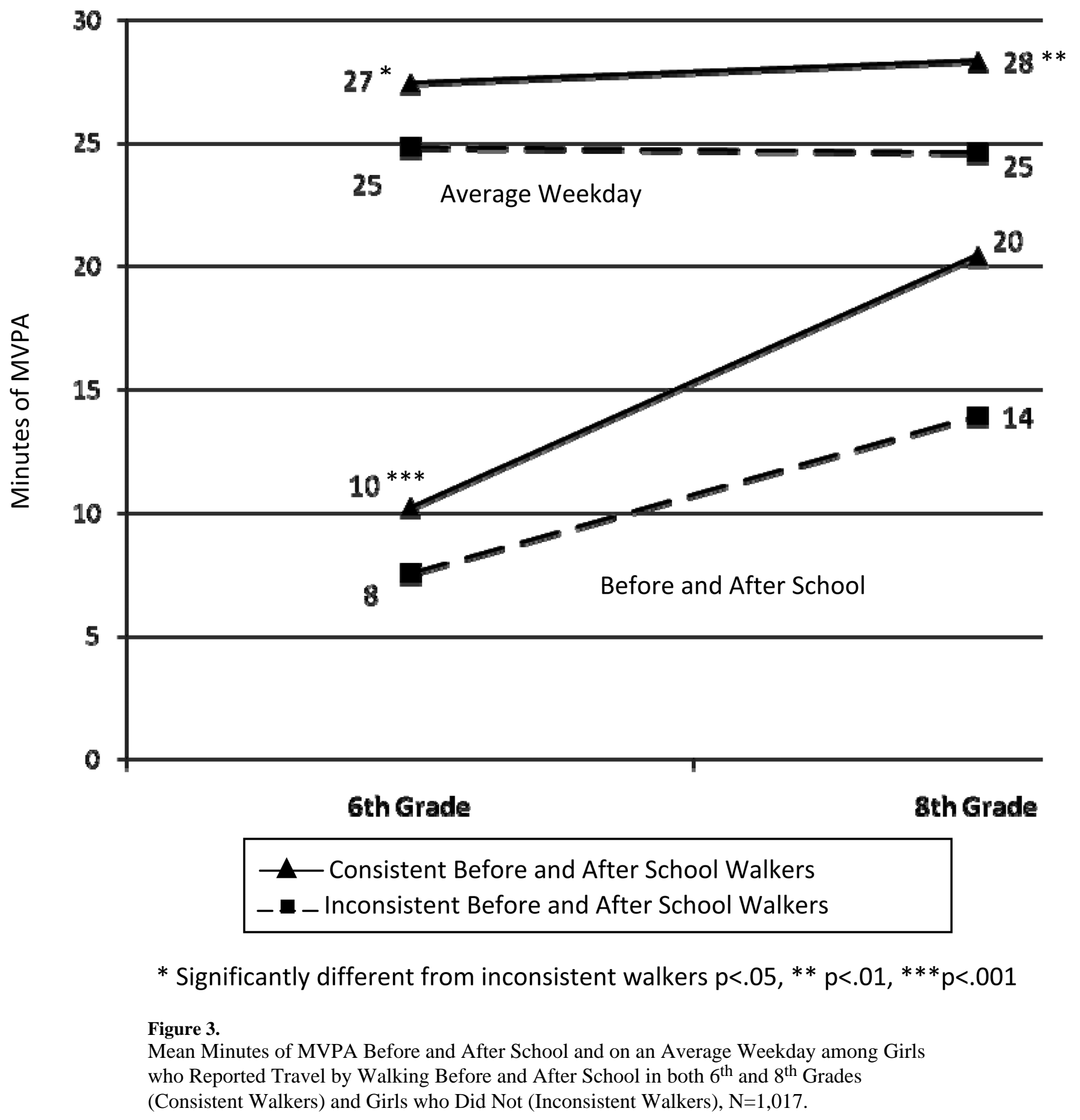


Table 1

Demographic, BMI and Neighborhood Information by Travel by Walking Before or After School in $8^{\text {th }}$ Grade Girls in 2005, N=3,076 ${ }^{\dagger}$

\begin{tabular}{|c|c|c|c|}
\hline & $\begin{array}{c}\text { Travel by } \\
\text { Walking Not } \\
\text { Reported } \\
(\mathbf{n}=\mathbf{2 1 3 2})\end{array}$ & $\begin{array}{c}\text { Travel by } \\
\text { Walking } \\
\text { Reported } \\
(\mathbf{n}=944)\end{array}$ & $\begin{array}{c}\text { P- } \\
\text { value }^{f}\end{array}$ \\
\hline BMI, $\mathrm{kg} / \mathrm{m}^{2}$ & $22.7(0.4)$ & $22.9(0.4)$ & .37 \\
\hline \multicolumn{4}{|l|}{ Race/Ethnicity, No. (\%) 1} \\
\hline White & $1053(74.5)$ & $360(25.5)$ & $<.001$ \\
\hline African American & $464(69.1)$ & $207(30.8)^{* *}$ & \\
\hline Hispanic & $389(60.8)$ & $251(39.2)^{* * *}$ & \\
\hline Multi-race/other & $226(64.2)$ & $126(35.8)^{* * * *}$ & \\
\hline Do you get free or low-cost lunches at school? (\% Yes) 1,2 & $749(35.5)$ & $387(42.0)$ & .01 \\
\hline \multicolumn{4}{|l|}{ Perceptions of Neighborhood } \\
\hline There are bicycle or walking trails in my neighborhood. & $3.1(0.1)$ & $3.3(0.1)$ & .07 \\
\hline There are many places I like to go within easy walking distance of my home. & $3.5(0.3)$ & $3.8(0.1)$ & $<.001$ \\
\hline Walkers and bikers on the streets in my neighborhood can easily be seen by people in their homes. & $3.8(0.1)$ & $3.8(0.1)$ & .32 \\
\hline There are sidewalks on most of the streets in my neighborhood. & $3.5(0.3)$ & $3.6(0.3)$ & .01 \\
\hline It is safe to walk or jog in my neighborhood. & $3.9(0.1)$ & $4.0(0.1)$ & .16 \\
\hline There is so much traffic that it makes it hard to walk in my neighborhood. & $1.9(0.05)$ & $1.9(0.1)$ & .27 \\
\hline There is a lot of crime in my neighborhood. & $1.9(0.1)$ & $1.9(0.1)$ & .40 \\
\hline I often see other girls or boys playing outdoors in my neighborhood. & $3.7(0.1)$ & $3.7(0.1)$ & .74 \\
\hline There are many interesting things to look at while walking in my neighborhood. & $3.2(0.1)$ & $3.1(0.1)$ & .92 \\
\hline My neighborhood streets are well lit at night. & $3.0(0.2)$ & $3.1(0.2)$ & .69 \\
\hline \multicolumn{4}{|l|}{ GIS Variables } \\
\hline Distance to School (miles) ${ }^{1}$ & $2.9(0.1)$ & $2.4(0.1)$ & $<.001$ \\
\hline Neighborhood Population Density (1/2 mi) & 2065 (126) & $2023(129)$ & .31 \\
\hline Neighborhood Connectivity & $-0.1(0.7)$ & $0.1(0.7)$ & .01 \\
\hline
\end{tabular}

${ }^{1}$ Sample sizes differ slightly due to missing variables.

2 This is a measure of SES.

${ }^{\dagger}$ Data are given as mean (SE) unless otherwise indicated.

${ }^{\sharp} P$ value for Analysis of Variance test of equality of means between walkers and non-walkers, controlling for site and school.

*** Significantly different from White girls $\mathrm{p}<.01$;

**** $\mathrm{p}<.001$ 
Table 2

Mean Minutes of Daily Physical Activity and Sedentary Behavior in $8^{\text {th }}$ Grade Girls Who Did and Did Not Report Travel by Walking Before or After School ${ }^{1}, \mathrm{~N}=3,076$

\begin{tabular}{|c|c|c|c|c|}
\hline & $\begin{array}{r}\text { Travel by } \\
\text { Walking } \\
\text { Not } \\
\text { Reported } \\
(\mathrm{n}=\mathbf{2 1 3 2})\end{array}$ & $\begin{array}{r}\text { Travel by } \\
\text { Walking } \\
\text { Reported } \\
(\mathbf{n}=944)\end{array}$ & $\begin{array}{c}\text { P- } \\
\text { Value }\end{array}$ & $\begin{array}{c}\text { Differences in } \\
\text { minutes } \\
(95 \% \mathrm{CI})\end{array}$ \\
\hline \multicolumn{5}{|l|}{ Before school } \\
\hline Total Physical Activity & $37.4(1.1)$ & $37.5(1.2)$ & .82 & $0.15(-1.1$ to 1.4$)$ \\
\hline MVPA (3 METs) & $11.3(0.6)$ & $13.2(0.7)$ & $<.001$ & $1.9(-0.77$ to 2.9$)$ \\
\hline MVPA $^{2}$ & $3.4(0.4)$ & $5.0(0.5)$ & .001 & $1.6(0.66$ to 2.6$)$ \\
\hline Duration of longest bout of MVPA (3 METs) & $15.4(3.8)$ & $24.4(4.7)$ & .05 & $9.0(.01$ to 18.0$)$ \\
\hline Total Sedentary Minutes & $90.9(5.1)$ & $90.9(5.2)$ & .94 & $.05(-1.3$ to 1.2$)$ \\
\hline \multicolumn{5}{|l|}{ After school } \\
\hline Total Physical Activity & $59.6(3.2)$ & $60.6(3.3)$ & .22 & $1.0(-0.61$ to 2.6$)$ \\
\hline MVPA (3 METs) & $18.8(1.4)$ & $22.5(1.4)$ & $<.001$ & $3.7(2.4$ to 5.0$)$ \\
\hline MVPA & $6.1(0.7)$ & $8.6(0.8)$ & $<.001$ & $2.5(1.4$ to 3.7$)$ \\
\hline Duration of longest bout of MVPA (3 METs) & $17.3(2.0)$ & $25.8(2.4)$ & $<.001$ & $8.5(3.9$ to 13.0$)$ \\
\hline Total Sedentary Minutes & $71.5(4.4)$ & $70.4(4.5)$ & .20 & $-1.1(-2.8$ to -0.6$)$ \\
\hline \multicolumn{5}{|l|}{ Before and after school } \\
\hline Total Physical Activity & $96.9(3.5)$ & $98.1(3.6)$ & .35 & $1.1(-1.3$ to 3.6$)$ \\
\hline MVPA (3 METs) & $30.1(1.7)$ & $35.7(1.8)$ & $<.001$ & $5.6(3.4$ to 7.8$)$ \\
\hline MVPA & $9.5(1.0)$ & $13.6(1.2)$ & $<.001$ & $4.1(2.1$ to 6.1$)$ \\
\hline Total Sedentary Minutes & $162.4(3.8)$ & $161.3(3.8)$ & .37 & $-1.1(-3.6$ to 1.4$)$ \\
\hline \multicolumn{5}{|l|}{ Average Weekday } \\
\hline Total Physical Activity & $338.0(4.8)$ & $338.5(5.1)$ & .84 & $0.5(-4.4$ to 5.4$)$ \\
\hline MVPA (3 METs) & $91.3(3.1)$ & $95.0(3.2)$ & .01 & $3.7(0.77$ to 6.7$)$ \\
\hline MVPA & $23.6(1.8)$ & $25.6(1.8)$ & $<.001$ & $2.1(1.1$ to 3.1$)$ \\
\hline Total Sedentary Minutes & $562.6(4.4)$ & $561.0(4.7)$ & .54 & $-1.6(-6.7$ to 3.5$)$ \\
\hline
\end{tabular}

Abbreviations: $\mathrm{MET}=$ Metabolic equivalent; $\mathrm{MVPA}=$ moderate to vigorous physical activity

1,"Before school" is defined as 6AM to school start-bell time; "after school" refers to school end-bell time to 5 PM.

2 MVPA=4.6 METs

tData are given as mean (SE).

${ }^{*} P$ value for Analysis of Variance test of equality of means between walkers and non-walkers, controlling for site, school, SES, and race/ethnicity 